\section{Putting you first: how to manage body and mind to avoid burnout, depression and other negatives}

\section{Dave Nicol}

The job of being a veterinary surgeon is hard on both body and mind. If not managed carefully then the daily efforts required by veterinary surgeons can and do wear many professionals down, leading to mental, emotional and physical exhaustion. Those affected inevitably enter a negative feedback loop that results in poor performance, low esteem and unhappiness (and worse).

In this presentation Dr Dave Nicol explores the topic and looks into the emotional triggers and internal story telling that lead to this outcome. And will show delegates how to successfully rewire their thinking. Delegates will learn the classic signs of burnout. They will also explore the part that emotions, beliefs and internal storytelling play in the development of a poor emotional state.

They will learn some effective tools that will allow them to recognize:

- Risk moments

- How to spot a poor story or belief

- What things can contribute to a poor emotional state and create anxiety

Delegates will also then learn some highly effective tools to manage mental state and to become more resilient in the face of challenge. These fall into two categories:
Mental judo - managing the internal dialogue and telling a better story

- Daily habits to improve mental state

\section{KEY LEARNING OBJECTIVES}

- For delegates to clearly understand that burnout is a sign of a mismanaged mental and physical state and to be absolutely clear who is responsible for managing this state

- To understand the contributors to anxiety and the warning signs of running in the red 'danger zone'

- To be able to effectively deploy countermeasures to be able to handle the daily routine events that are unavoidable, but with the right mindset can be handled effectively without mental harm

\section{MULTIPLE CHOICE QUESTIONS}

1. Which of the following is NOT a sign of a negative mental state?
(A) Tiredness
(B) Irritability
(C) Singing out loud in the shower
(D) Poor sleep

2. Who has the greatest responsibility for your mental and physical health?
(A) Your boss
(B) The government
(C) The RCVS
(D) You

3. Which of the following does NOT help your mental state?
(A) Sleep
(B) Spending time with people you love
(C) Walking in nature
(D) Social media

\section{Personal branding for vets: why you need one and how to become the local pet celebrity}

\section{Dave Nicol}

Personal brands are everywhere nowadays with influencers changing the course of businesses in every field and facet of business. Veterinary medicine is no different. While the older generation seem to have avoided or ignored social tools, the same cannot be said of the millennials, who are embracing the technology with both hands.
Customers do business with those people and brands they know, trust and like. So a personal brand can be a massive tool to support and accelerate the career of any savvy young veterinary surgeons out there.

A personal brand is developed when an individual starts to create content that is noteworthy and other people start to take notice of and follow. So it is not for the feint hearted. Most will not have the determination to put in the work required. And many will run from the spotlight, but for those willing to engage, they sky is the limit.

Content creation is the basis of any personal branding strategy. This content can come in many forms: words, sounds, video and images. A good strategy will take advantage of as many formats as possible. My advice is to publish content to a blog or Youtube channel every week or a Facebook/Instagram page every day. Anything less and you are invisible.

Here are three techniques I rely on that will work for you too.

- Ahink about your audience first. What do they want, what do they need? What do they love or hate? 


\section{Management}

What keeps them awake or drives them crazy about animals. What things get them super-curious? What makes them laugh? What things make them go 'awwww' about their pets? Write about things that evoke emotions not put people to sleep

- Your story is amazing, so tell it. veterinary surgeons have a gift that many business owners would kill for - subject matter that is genuinely interesting. Saving lives is sexy. Pets are engaging (which is why kittens dominate the internet). Our path in life is an emotional journey, an engaging soap opera unfolding before our eyes daily. The simplest way to write a meaningful blog is to simply describe the things you see and do each day. Just do so with the pet owner in mind. They are unlikely to care about the specific technique you used to repair the problem. But they will care about the impact or your fears and hopes going into the surgery. Veterinary medicine is a wonderful daily mash-up of tragedy and comedy, use this to your advantage

- Write a list. 'Top Tips' articles are quick, easy and when done well, grab attention. Think of a topic. Start with the title and then the rest flows easily

Regardless of the technique you use to generate your content, the most important thing is simply having the will to meet your deadline whenever that falls. Most people fail because they lack the commitment and patience required to execute a content marketing strategy.

\section{KEY LEARNING OBJECTIVES}

- Understand what a personal brand is

- To understand some easy ways to begin generating the type of content required to build a personal brand

- To avoid the common pitfalls for those who wish to develop a personal brand

\section{MULTIPLE CHOICE QUESTIONS}

1. What is a personal brand?
(A) A tool that can help you build relationships with clients
(B) A way of differentiating yourself and increasing your value to a practice
(C) A strategy that requires you to have something useful to say
(D) All of the above

2. A personal brand can be built using which of the following?
(A) Blogs
(C) Instagram
(B) Youtube
(D) All of the above

3. People connect best with which of the following?
(A) Stories
(B) Facebook
(C) Youtube
(D) TV 